\title{
Acute Aneurysmal Subarachnoid Haemorrhage following Coital Headache successfully treated with Endovascular Flow Diversion
}

\author{
Apratim Chatterjee $D M^{1}$, Anshu Mahajan $D M^{2}$, Gaurav Goel $D M^{\mathfrak{3}}$, Piyush Ojha $D M^{4}$ \\ 1,2,3,4 Neuro-intervention, Medanta the Medicity, Gurugram, Haryana, India
}

Date of submission: $15^{\text {th }}$ October 2020

Date of acceptance: $31^{\text {st }}$ January 2021

Date of publication: $1^{\text {st }}$ March 2021

\begin{abstract}
Headache associated with sexual activity is a difficult diagnosis for physicians and sometimes underlies grave aetiologies. One such cause associated with high morbidity and mortality is subarachnoid haemorrhage due to ruptured aneurysm.

This is a case of a 39 year old male, presenting with coital headache for few episodes. Computed Tomography scan showed subarachnoid haemorrhage (Fischer Grade 3).

Digital subtraction angiography revealed very small aneurysm on right internal carotid artery which was endovascularly managed with flow-redirection endoluminal device (FRED, Microvention, Aliso Viejo, California, USA) flow diverter placement across the aneurysm. Follow up revealed complete resolution of aneurysm with no residual clinical symptoms. The following case reveals the importance of identifying sexual headache as a presenting symptom of a grave aetiology like aneurysmal rupture and its early diagnosis and management to avoid mortality.
\end{abstract}

Key words: Aneurysm, Coital headache, Flow Diverter, Subarachnoid hemorrhage

Access this article online
Website: https://www.nepjol.info/index.php/NJN
DOI: https://doi.org/10.3126/njn.v18i1.32950
HOW TO CITE
Chatterjee A, Mahajan A, Goel G, Ojha P. Acute Aneurysmal
Subarachnoid Haemorrhage following Coital Headache
successfully treated with Endovascular Flow Diversion. NJNS.
$2021 ; 18(1): 57-60$.

${ }^{1}$ ORCID id: 0000-0001-6312-0825

${ }^{2}$ ORCID id: 0000-0003-3261-9812

${ }^{3}$ ORCID id: 0000-0003-2871-7153

${ }^{4}$ ORCID id: 0000-0001-7659-0383

\author{
Address for correspondence: \\ Dr. Gaurav Goel \\ Medanta the Medicity, \\ 6Th Floor, OPD Room No 16, \\ Medicity, Islampur Colony, Sector 38, \\ Gurugram, Haryana 122001, India \\ Tel: +91-9650789820 \\ E-mail: drgauravgoel1@gmail.com
}

Copyright (C) 2021 Nepalese Society of Neurosurgeons (NESON)

ISSN: 1813-1948 (Print), 1813-1956 (Online)

This work is licensed under a Creative Commons

Attribution-Non Commercial 4.0 International License.

\section{Introduction}

T eadache due to sexual activity (HASA) is a dilemma 1 in the field of cephalalgia. Though headache with sexual activity has been described from the time of Hippocrates ${ }^{1}$, it has been in literature as early as the $1970 .^{2-4}$

It may be primary as well as due to other secondary illness. As per International Classification of headache disorders( ICHD) primary headache with sexual activity coded as 7.2.3 has specific diagnostic criteria.

However all headache with sexual activity before being stamped as primary should be ruling out any disturbance of consciousness, vomiting, visual, sensory or motor symptoms. It is also mandatory to rule out subarachnoid haemorrhage, intra and extra arterial dissection and reversible cerebral vasoconstriction syndrome (RCVS). Though two subtypes were identified in ICHD-I and ICHD-II respectively as pre-orgasmic and orgasmic headache subtypes respectively, the ICHD-III identifies primary headache associated with sexual activity as a single entity with variable presentation..$^{6-9}$

Various other causes some very grave are the most important part in its diagnosis as early and correct diagnosis to the condition may alter the course of the disease. These are aneurysms with or without subarachnoid haemorrhage 


\section{Chatterjee et al}

(SAH) [sometimes presenting as sentinel headache], spontaneous intracranial hypotension (probably due to CSF leakage), reversible cerebral vasoconstriction (RCVS) etc. ${ }^{9,10}$

The case described is of one such young male patient who presented similarly and the underlying cause and its further management helps to throw light on the importance of such a history for the clinician.

\section{Case}

A 39 year male, smoker (smoking 10 cigarettes per day for almost 7 years), without any-comorbidities presented to us with complain of repeated several bouts of intense headache during the orgasmic part of coitus for last 2 weeks for around 4 times. The headache was described as dull, initially around the posterior part of cranium and then gradually involving holocranium, thereby converting into intense throbbing headache. It peaked within a minute approximately and lasted for around 10 minutes even after stopping coitus. The headache was stereotypical in all the episodes so far and was not associated with redness, lacrimation in eyes, or rhinorrhoea.
On admission for further evaluation patient was conscious, alert, cooperative without any neurological deficits. Detailed neurological assessment did not reveal any focal neurological deficit except mild neck rigidity with positive Kernigs and Brudzinskisign. Pupils were 3 $\mathrm{mm}$ in size and bilaterally normally reacting.

Computed tomography (CT) brain was done at triage which revealed a Subarachnoid haemorrhage (Fischer Grade 3).The patient was then taken to cath lab for a digital Subtraction Angiography (DSA) which revealed a very small aneurysm ( Fig. 1) measuring $1.1 \mathrm{~mm} \times 08 \mathrm{~mm}$ with neck measuring approximately $1 \mathrm{~mm}$ in the right internal carotid artery in the ophthalmic segment along the posterior wall. The aneurysm was directed posteriorly. As the location was intradural and corroborated with location of SAH seen in CT scan, a causal role to the clinical indicator of coital headache as a clinical marker of rupture of this aneurysm was brought into picture. The patient and the attendants were counselled accordingly about the management of this "side wall"11 aneurysmal $\mathrm{SAH}$ and the option of flow diverter ${ }^{12}$ was given. A multidisciplinary team meeting was done to decide for further management including Neurosurgical team and neuro-intervention team. Although surgical option was

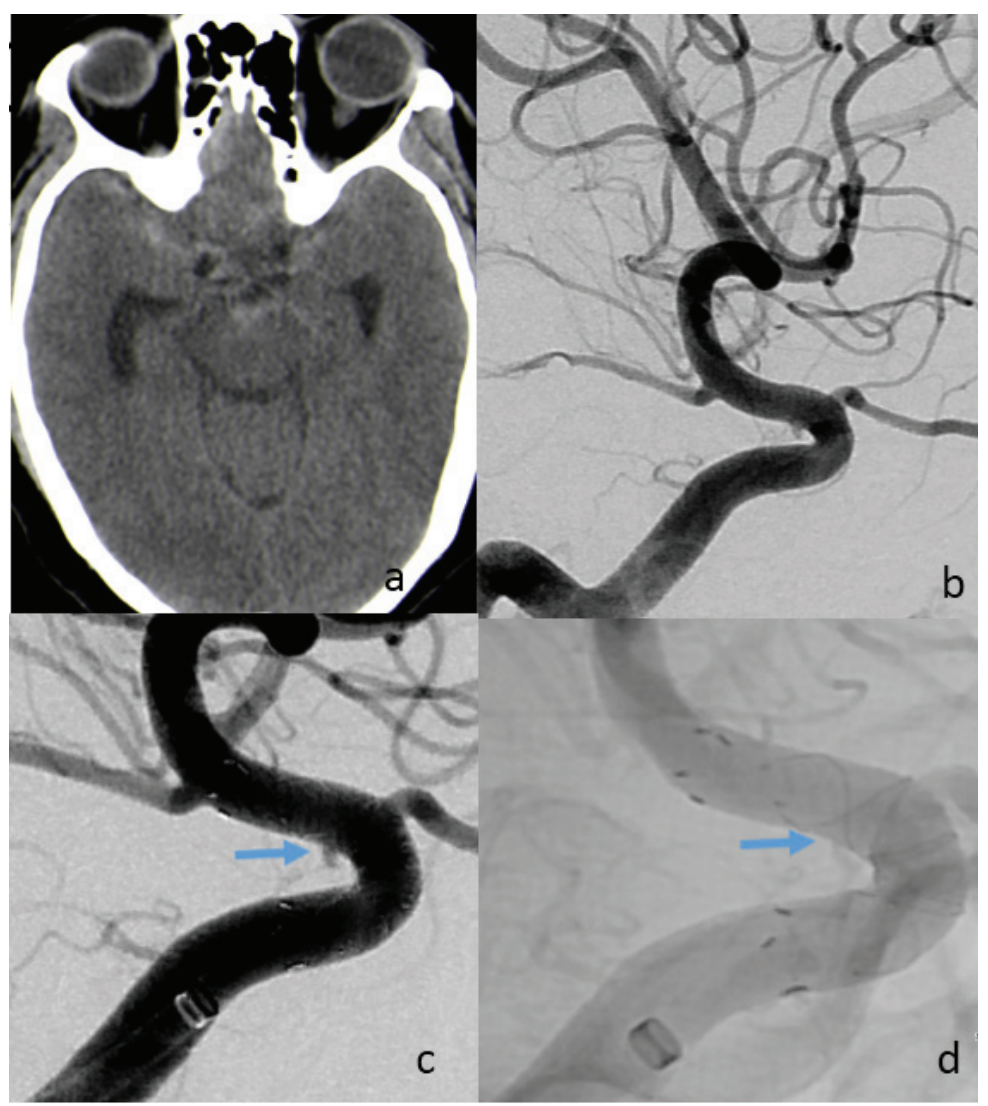

Figure I(a). CT scan brain shows acute subarachnoid haemorrhage. (b) and (c) shows small aneurysm in the ophthalmic segment of right ICA. (d) (native image) shows FRED flow diverter placement across the aneurysm in ICA. 


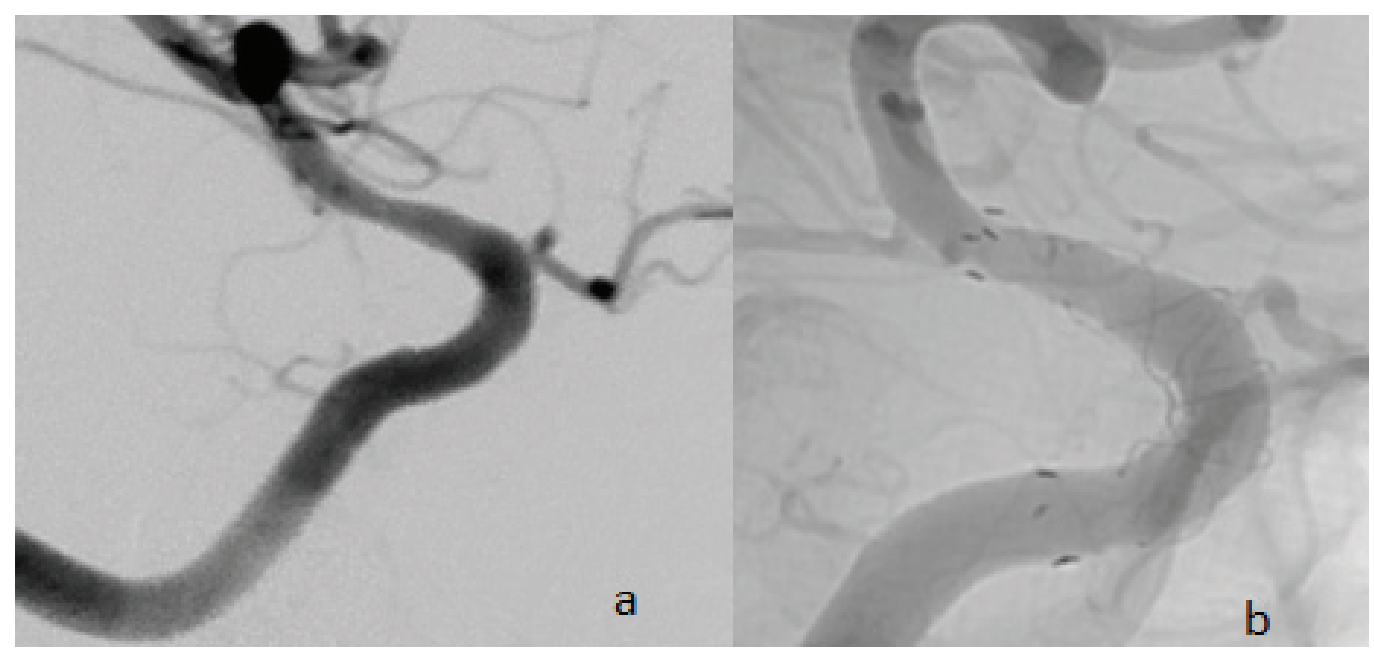

Figure $2 a$ and $b$ [native image] shows complete resolution of aneurysm on follow up after 3 months.

given to attendants, considering relatively high risk of the surgical management in the location of aneurysm in this particular case, family themselves had opted for endovascular management considering the evidence available for relative safety and efficacy of flow diverter for such sidewall small aneurysm. ${ }^{12}$ The use of other stents would have never served the purpose of flow diversion, hence was not considered in this case.

The patient gave informed consent and was loaded with tablet Asprin $300 \mathrm{mg}$ and tablet Prasugrel 50 $\mathrm{mg}$ on the morning of the procedure. Under general anaesthesia, right femoral artery was accessed and 6 French long sheath was placed into the right common carotid artery over a 5 French Picard catheter over 035 Terumo guidewire. Following this, 070 Distal Access Catheter (DAC) was placed into the petrous segment of right internal carotid artery. Subsequently flow-redirection endoluminal device (FRED) (Microvention, Aliso Viejo, California, USA) flow diverter $(4 \mathrm{mmx} 12 \mathrm{~mm} \times 18 \mathrm{~mm})$ was placed across the neck of the aneurysm with the help of Headway 27 microcatheter (Microvention, Aliso Viejo, California, USA) ( FIG $1 \mathrm{c}$ and d).

The patient was discharged after 10 days in fully ambulatory state and was discharged on Tablet Asprin 150 $\mathrm{mg}$ and Tablet Prasugrel $10 \mathrm{mg}$ daily till 6 months and was planned for follow up at 3 months. Follow-up after 3 months showed complete obliteration of the aneurysm (Fig $2 \mathrm{a}$ and $\mathrm{b}$ ) and clinical history with examination revealed complete resolution of headache with no neurological deficits.

\section{Discussion}

The patient presented with features of HASA. The presentation is important because apart from being primary, secondary causes need to be ruled out. One of the most important and deadly causes being SAH and the presentation is a must to identify and diagnose such illness at the earliest which is often lifesaving.

The above case also had a SAH. DSA revealed a small aneurysm in the ophthalmic segment of Right Internal carotid artery which matched with CT scan of brain with the possible site of rupture.After consent flow diverter was placed across the aneurysm. The Flow Direction Endoluminal Device (FRED) (Microvention, Aliso Viejo, California, USA) is a double-layer flow diverter with a stent-like outer layer and a flow diverter part inside the stent. This design enhances the navigability of the device, especially in tortuous anatomy and apposition of the device to the arterial wall, a key point in achieving aneurysm occlusion.

Sexual activity causes fluctuation in blood pressure and sometimes increases the mean arterial pressure seriously as high as $130-175 \mathrm{mmHg}$ in males and $125-160 \mathrm{mmHg}$ in females which can cause the rupture of aneurysm. ${ }^{13-14}$ Increased level of nor-adrenaline and blood pressure enhance the risk of aneurysm rupture. Furthermore, it was shown that the vertical increase of blood pressure by sexual activity enhanced the risk of aneurysm rupture. ${ }^{15,16}$

Mann et al reported high blood pressure rates during sexual activity in 11 cases in 18 sexual activity episodes. In these episodes they figured out the peak arterial pressure $300 / 175 \mathrm{mmHg}$ and mean arterial pressure $237 / 138 \mathrm{mmHg}$ for males and 216/127 mmHg for females. ${ }^{16}$ Furthermore; in another study Littler et all showed that peak arterial pressure might reach $233 / 128 \mathrm{mmHg}$ by sexual activity in 7 normotensive cases. ${ }^{17}$ As well as in a study by Kriz et al; ${ }^{18} \mathrm{SAH}$ were determined in 51 cases those had neurologic complication at the time of sexual activity. ${ }^{18}$ 


\section{Chatterjee et al}

Even HASA presentation without subarachnoid haemorrhage on CT scan of brain but with unruptured ICA aneurysm has been reported in literature. Several pathophysiological mechanisms have been proposed to explain this type of headache, like occurrence of thrombosis or local expansion of the aneurysm, interior bleeding in its wall, and meningeal inflammatory reaction. ${ }^{14}$

Other pathophysiology like muscular contraction leading to headache with sexual activity has been mentioned. ${ }^{13,14}$

Whatever be the cause, HASA is associated with decreased sexual drive and poor performance during sexual activity. However apart from the decreased sexual pleasure the fact that a hidden life threatening cause may underlie is also very important as in this case.

\section{Conclusion}

Subarachnoid haemorrhage caused by aneurysm rupture has been seen to occur during sexual activity. These cases have high morbidity and mortality. Early identification is the key and prompt management helps to decrease morbidity and mortality. The importance of this case is the presentation of HASA as subarachnoid haemorrhage due to rupture of a small ophthalmic segment ICA aneurysm and its successful endovascular management leading to clinical recovery.

Conflict of Interest: None

Source(s) of support: None

\section{References}

1. Adams F. The genuine works of Hippocrates. London: Sydenham Society 1848.

2. Lance JW. Headaches occurring during sexual intercourse. Proc Aust Assoc Neurol 1974; 11:57-60. PMID: 4469639

3. Martin EA. Headache during sexual intercourse (coital cephalalgia). Ir J Med Sci 1974; 143:342-5. https://doi.org/10.1007/BF03004787

4. Paulson GW, Klawans HL. Benign orgasmic cephalgia. Headache 1974; 13:181-7.https://doi. org/10.1111/j.1526-4610.1974.hed1304181.x

5. Ostergaard JR, Kraft M. Natural course of benign coital headache. BMJ. 1992; 305:1129.https://doi. org/10.1136/bmj.305.6862.1129

6. Frese A, Rahmann A, Gregor N, Biehl K, Husstedt IW, Evers S. Headache associated with sexual activity:Prognosis and treatment options. Cephalalgia. 2007; 27:1265-1270.https://doi.org/10.1111/j.14682982.2007.01449.x
7. Qureshi AI, Fareed M, Suri K, et al. Effect of endovascular treatment on headaches in patients with unruptured intracranial aneurysms. Headache. 2003; 43:1090-1096.https://doi.org/10.1046/j.15264610.2003.03211.x

8. Kong D-S, Hong S-Ch, Jung Y-J, Kim JS. Improvement of chronic headache after treatment of unruptured intracranial aneurysms. Headache. 2007; 47:693-697. https://doi.org/10.1111/j.1526-4610.2006.00630.x

9. Schwedt TJ, Matharu MS, DodickDW.Thunderclap headache. Lancet Neurol. 2006; 5:621-631.https:// doi.org/10.1016/S1474-4422(06)70497-5

10. Frese A, Eikermann A, Frese K, Schwaag S, Husstedt I-W, Evers S. Headache associated with sexual activity. Demography, clinical features, andcomorbidity.Neurology2003;61:796-800.https:// doi.org/10.1212/01.WNL.0000083988.98336.A3

11. Baharoglu, M. I.; Lauric, A.; Gao, B. L. \& Malek, A. M. Identification of a dichotomy in morphological predictors of rupture status between sidewall- and bifurcation-type intracranial aneurysms. J. Neurosurg., 116(4):871-81, 2012. doi: 10.3171/2011.11. JNS11311.

12. D’Urso PI, Lanzino G, Cloft HJ, Kallmes DF. Flow diversion for intracranial aneurysms: a review.Stroke. 2011; 42:2363-2368. doi: 10.1161/ STROKEAHA.111.620328. Epub 2011 Jul 7.

13. Martinez JM, Roig C, Arboix A. Complicated coital cephalalgia. Three cases with benign evolution. Cephalalgia. 1988; 8:265-268.https://doi. org/10.1046/j.1468-2982.1988.0804265.x

14. Reynolds MR, Willie JT, Zipfel GJ, Dacey RG. Sexual intercourse and cerebral aneurysmal rupture: potential mechanisms and precipitants. J Neurosurg 2011;114(4):969- 977.https://doi. org/10.3171/2010.4.JNS09975

15. VermeerSE, RinkelGJ,AlgraA.CircadianFluctuations in Onset of Subarachnoid Hemorrhage. New Data on Aneurysmal and PerimesencephalicHemorrhage and a Systematic Review. Stroke 1997;28(4):805-808. https://doi.org/10.1161/01.STR.28.4.805

16. Mann S, Craig MW, Gould BA, Melville DI, Raftery EB. Coital blood pressure in hypertensives: cephalgia, syncope, and the effects of beta-blockade. Br Heart J 1982;47(1):84-89.https://doi.org/10.1136/hrt.47.1.84

17. Littler WA, Honour AJ, Sleight P. Direct arterial pressure, heart rate and electrocardiogram during human coitus. J ReprodFertil 1974;40(2):321-331. https://doi.org/10.1530/jrf.0.0400321

18. Kriz K. Coitus as a factor in the pathogenesis of neurological complications. CeskNeurol 1970;33(3):162-167.PMID: 5443431. 